\title{
Retracted: Prognostic Utility of Coronary Computed Tomographic Angiography: A 5-Year Follow-Up in Type 2 Diabetes Patients with Suspected Coronary Artery Disease
}

\author{
Journal of Diabetes Research \\ Received 14 January 2015; Accepted 14 January 2015 \\ Copyright (C) 2015 Journal of Diabetes Research. This is an open access article distributed under the Creative Commons Attribution \\ License, which permits unrestricted use, distribution, and reproduction in any medium, provided the original work is properly cited.
}

\begin{abstract}
The paper titled "Prognostic Utility of Coronary Computed Tomographic Angiography: A 5-Year Follow-Up in Type 2 Diabetes Patients with Suspected Coronary Artery Disease" [1], published in Journal of Diabetes Research, has been retracted as it is found to contain a substantial amount of material from the published paper "Value of multi-detector computed tomography angiography in predicting acute cardiac events in patients with type 2 diabetes" by Daliang Liu, Huijuan Jia, Wei Liu, Daqing Ma, Guangshan Tan, Wen He, Yucun $\mathrm{Fu}$, and Le-Xin Wang, published in Experimental Therapeutic Medicine in April 2014.
\end{abstract}

\section{References}

[1] D. Liu, H. Jia, Y. Fu, W. He, and D. Ma, "Prognostic utility of coronary computed tomographic angiography: a 5-year followup in type 2 diabetes patients with suspected coronary artery disease," Journal of Diabetes Research, vol. 2014, Article ID 103459, 7 pages, 2014. 